\title{
Estimation of Impact Loads in a Hydraulic Breaker by Transfer Path Analysis
}

\author{
Changheon Song, ${ }^{1,2}$ Dae Ji Kim, ${ }^{2}$ Jintai Chung, ${ }^{1}$ Kang Won Lee, \\ Sang Seuk Kweon, ${ }^{2}$ and Young Ky Kang ${ }^{3}$ \\ ${ }^{1}$ Department of Mechanical Engineering, Hanyang University, 1271 Sa-1-Dong, Ansan, Kyunggi-Do, Republic of Korea \\ ${ }^{2}$ Construction Equipment R\&D Center, Korea Institute of Industrial Technology, Gyeongsan-si, Republic of Korea \\ ${ }^{3}$ ReD Center Breaker Development Team, Soosan Heavy Industries Co., Ltd, Hwaseong-si, Republic of Korea \\ Correspondence should be addressed to Sang Seuk Kweon; sskweon@kitech.re.kr
}

Received 13 June 2017; Accepted 27 August 2017; Published 22 November 2017

Academic Editor: Filippo Ubertini

Copyright (C) 2017 Changheon Song et al. This is an open access article distributed under the Creative Commons Attribution License, which permits unrestricted use, distribution, and reproduction in any medium, provided the original work is properly cited.

\begin{abstract}
The aim of this study is to estimate the impact loads delivered to the housing of a hydraulic breaker quantitatively. Striking forces caused vibrations in the equipment housing, which were experimentally measured, and frequency response functions were also found through modal impact experiments. Transfer path analysis (TPA) method of the data quantified the impact loads delivered to the housing. TPA method can analyze the relationship between the vibration energy and the transfer path of an excitation source and so explore the way in which vibrations on each path contribute to the entire vibration profile. The impact loads of each part derived by TPA method were compared with the impact loads in the chisel derived from strain gauge measurements of the striking energy. This comparison validated the TPA approach. This study describes the basic concepts and components of TPA method and also reviews its applicability to mechanical equipment that experiences impact vibrations and impact loads.
\end{abstract}

\section{Introduction}

Hydraulic breakers have various uses. For example, excavators often use them to fracture the ground or bedrock to produce materials or aggregates or to demolish structures (Figure 1(a)) $[1,2]$. A hydraulic breaker comprises a directional valve to control the direction of fluid flow, an accumulator to store the hydraulic energy and to supply the required flow during operation, a back head filled with nitrogen gas, pistons for delivering the striking energy to the chisel while performing a reciprocal motion, and a chisel that breaks the subject material directly. The hydraulic breaker is mounted on an excavator by a coupler (Figure 1(b)). The hydraulic breaker is a typical attachment commonly found at industrial and construction sites. As modern industrial technology develops, consumers demand higher standards. Therefore, industrial and construction equipment now requires high structural stability as well as intelligence, performance, and efficiency.

Recent studies of hydraulic breakers include the work of Ficarella et al. [3-5], who used a 1D simulation and experimental tests to investigate the performance and design of a hydraulic breaker. Several other studies have focused on improving performance, reducing the weight of the housing, and optimizing vibration and noise [6-8]. However, few studies have sought to quantify the impact loads delivered to the housing, even though these loads are closely related to the durability of the equipment. Among the numerous factors that determine the performance of a hydraulic breaker (the hydraulic circuit and the design of the striking piston, shuttle valve, etc.), the structural stability of the housing is directly related to the durability and lifespan of the equipment, making it one of the most important design factors. Hence, to predict the lifespan of the equipment and the durability of the housing effectively, the impact loads delivered to the housing during striking should be analyzed. Such analysis is important, because a hydraulic breaker often experiences extreme conditions in its various applications that see it constantly enduring impact vibrations and impact loads.

There are many methods for measuring static and impact loads such as using force sensors or strain gauges. Static 


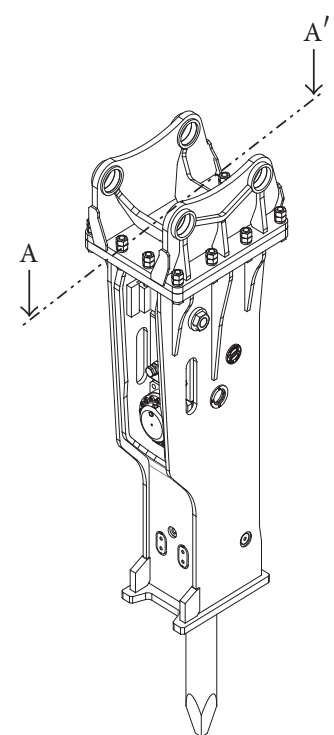

(a)

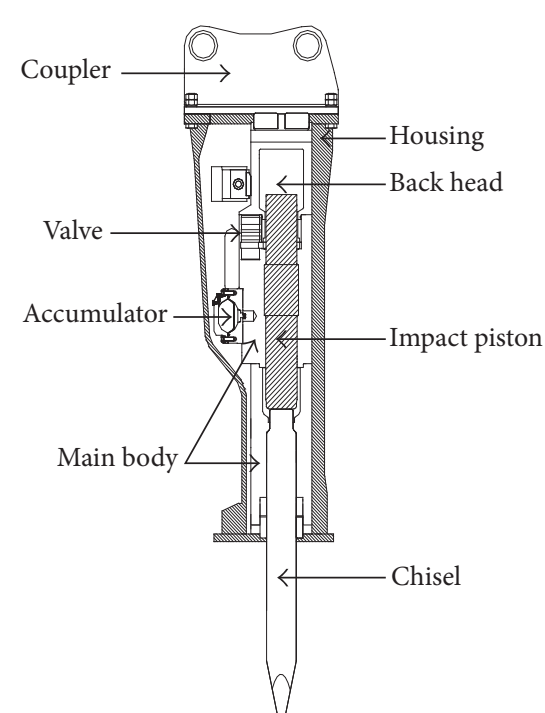

(b)

FIgURE 1: Schematic of the hydraulic breaker: (a) isometric view, (b) cross section A-A'.

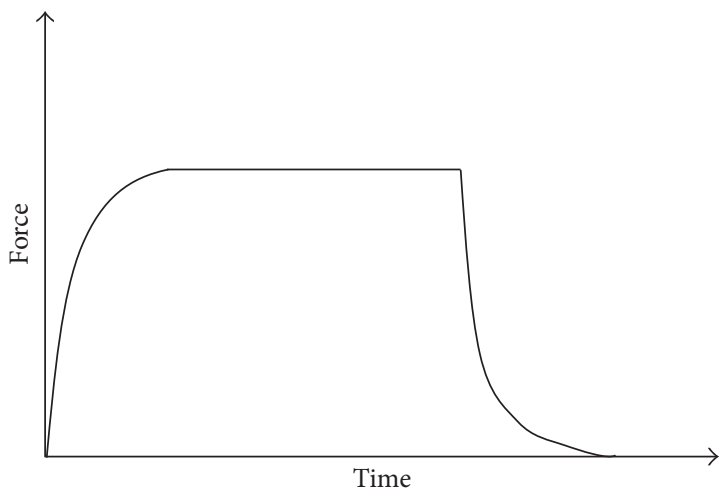

(a)

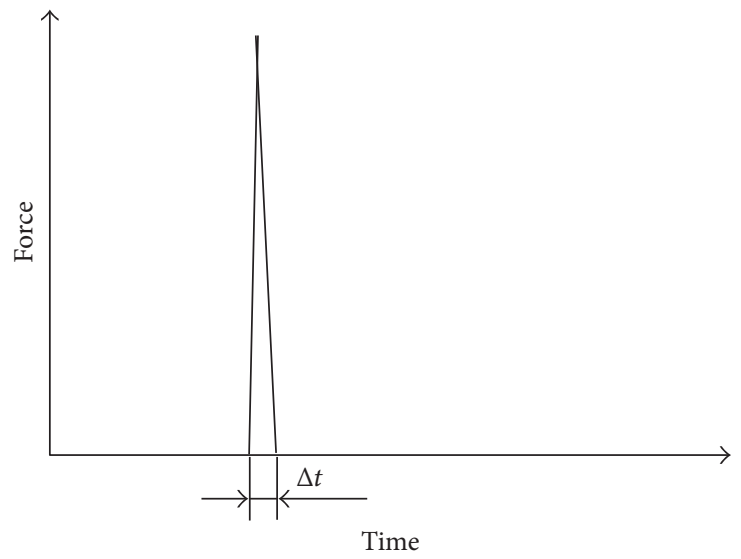

(b)

FIGURE 2: Generated force profiles: (a) general force, (b) impulse force.

loads are generally much easier to measure than impact loads, because measuring impact loads requires the additional consideration of the dynamic characteristics of the measuring instrument [9]. The measurement of impact loads is considered in various areas; one study recorded impact vibration data on a structure by measuring loads using load cells and strain gauges, and another predicted structural damage due to impact loads [10-16]. The previous studies were performed to investigate various factors, including the behavior of dynamical stress inside a structure; safety, the transfer of an impact load and energy to a rock from a striking object, such as a striking piston; structural damage prediction during the transfer of an impact load; and soil damage characteristics.

Furthermore, several studies have used transfer path analysis (TPA) to evaluate the impact transfer in a structure and to confirm the contribution of each impact transfer $[17,18]$. This approach is typically used to predict the force contribution and sound power level of a vibration (excitation) source to improve the characteristics of noise, vibration, and harshness, to decrease the noise in a vehicle's interior or reduce engine noise generally $[19,20]$, or to calculate the loads in structures that generate loads, such as automobile parts (Figure 2(a)). However, no study has applied this approach to construction machinery, where impact vibrations and impact loads are generated during normal operation. This is mainly due to the difficulty in performing the necessary direct measurements because of the tendency of the strain gauges to break away or because of other problems, such as the overloading of load cells and installation problems caused by the operation of construction equipment and attachments (e.g., rock breaking and drilling, surface mining, and soil excavation) [21]. The present study evaluates the validity of TPA in its application to 


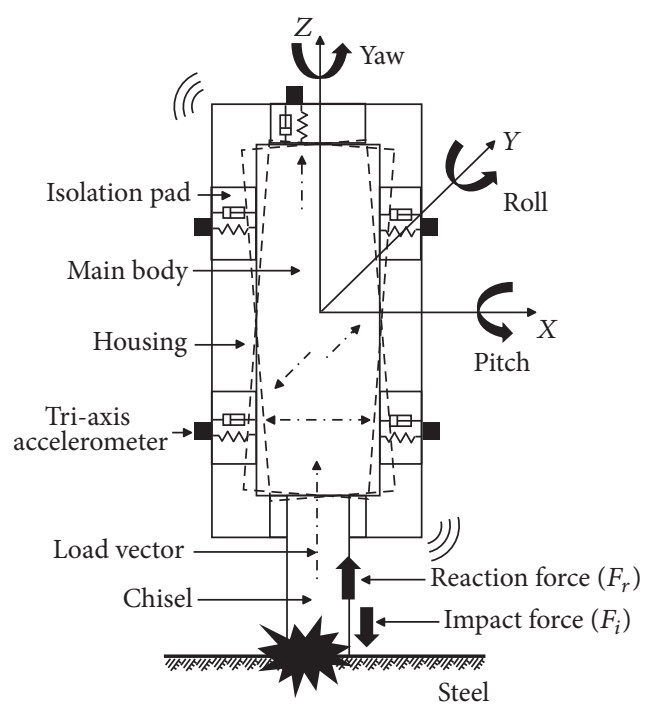

Figure 3: Motion of hydraulic breaker due to impact load.

a structure, generating impact loads with very short durations (Figure 2(b)).

This study evaluates the applicability of TPA to a hydraulic breaker and quantitatively assesses the impact loads generated during striking. The striking impact loads are defined as the loads delivered to the housing across an isolation pad. The direction of the main loads applied by the hydraulic breaker follows the $z$-axis. However, the impact loads to the housing are delivered during pitch, roll, and yaw motions, which arise due to the vibrations of the main body caused by the striking (Figure 3 ). The basic concept and components of TPA are examined here, and the applicability of TPA to mechanical equipment with impact vibrations and impact loads is discussed. In addition, the vibration characteristics occurring during striking and the frequency response functions (FRFs) obtained through modal impact experiments are applied to the TPA. Consequently, the impact loads occurring during the striking of the hydraulic breaker and the respective contributions to the load transfer in each component of the hydraulic breaker are evaluated. Additionally, the impact loads of each component derived from the TPA approach are compared with those in the chisel derived by the striking energy measured by using strain gauges. The comparison verifies the validity of applying TPA to structures experiencing impact loads and vibrations.

\section{Vibration Experiments Using a Hydraulic Breaker}

2.1. Theoretical Background of TPA. TPA is useful for understanding the major transfer path of noise and vibration energy generated by an excitation source. It is also important for experimentally assessing the sensitivity of each component to the transfer path [17]. TPA considers two separate, basic concepts: structure-borne noise measured by an acoustic receiver and airborne noise [22]. Structure-borne noise is delivered by vibrations through the structure, whereas the airborne noise is delivered via air [17]. The basic concepts of TPA for each component are expressed mathematically in (1). The respective noise and vibration can be defined as the product of the transfer functions about the excitation source and transfer path as

$$
P_{t}(\omega)=\sum_{i=1}^{n} \operatorname{VTF}_{i}(\omega) \cdot F_{i}(\omega)+\sum_{j=1}^{r} \operatorname{NTF}_{j}(\omega) \cdot Q_{j}(\omega)
$$

where $F_{i}(i=1, \ldots, n)$ and $Q_{j}(j=1, \ldots, r)$ denote the interface forces due to structural vibration loads and volume velocities due to acoustic loads, respectively, and $\mathrm{VTF}_{i}$ and $\mathrm{NTF}_{j}$ are the transfer functions for structural vibrations and airborne noise, respectively. The basic TPA model assumes that the global system can be divided into an active and a passive part: the active part containing the sources and the passive part containing the transmission paths and receiver points. A schematic representation is shown in Figure 4 [21]. At the interface between the two parts, the structural or acoustic loads can be defined depending on the type of coupling. These excitations are then propagated to receiver points through the transfer parts. Generally, the loads are interface force $(F)$ or volume velocities $(Q)$ (e.g., in the engine mount or the air intake orifice), and receiver responses are sound pressure $\left(P_{t}\right)$ or acceleration (e.g., sound at the driver's ear or steering wheel vibration).

The transfer paths are represented by their corresponding FRFs, which are often called noise transfer functions. Each of them describes the relationship between one input degree-offreedom (DoF) and one response DoF. There is also a second group of FRFs in the model, denoted by $H_{p i}$ in Figure 4, and they are usually referred to as local FRFs. These FRFs express the relationship between the responses at the input DoFs $\left(a_{p n}, p_{j}\right)$ and also at additional response locations called over determination points $\left(a_{p k}\right)$. This model presumes a causal load-response relationship and that all the FRFs are system characteristics of the global system [21]. 

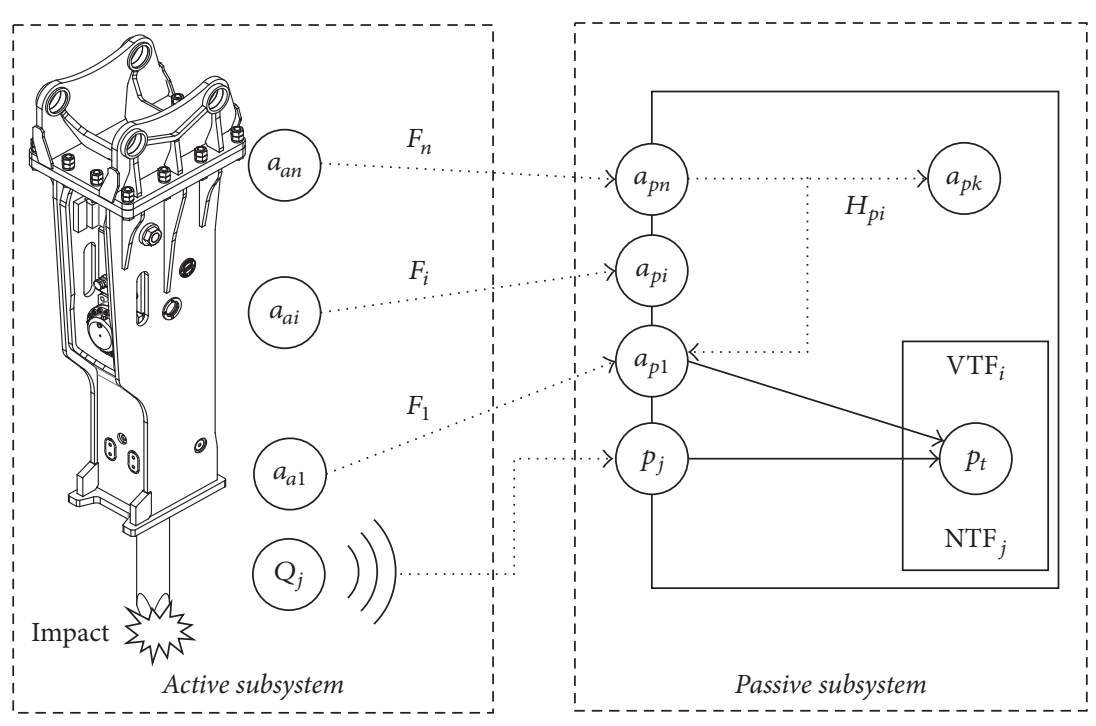

FIGURE 4: Schematic of transfer path analysis model; active subsystem generating force and acoustic loads and a passive subsystem responding to these loads (modified from Gajdatsy et al. [21]).

The TPA approach for load estimation varies with the purpose and subject of the experiment, with approaches including direct measurement, dynamic stiffness, matrix inversion, and intensity methods [23, 24]. Figure 5(a) shows the process for quantifying the excitation force and sound power. Data were either measured directly using sensors or indirectly derived using the measured data. Data for the sound power were acquired by direct measurements using the surface area and surface velocity, or indirectly using the intensity method and matrix inversion. Excitation force was indirectly measured by using the dynamic stiffness and matrix inversion methods. The transfer function for structure-borne noise was measured with an impact hammer or an exciter, whereas the transfer function for airborne noise was measured by the volume velocity sources [21, 23, 25].

2.2. Methodologies. The transfer path can be determined by analyzing the frequency domain or the time domain, depending on the method for analyzing the signal. This study uses frequency domain method to check the contribution of the path in each frequency, and it also uses time domain method to check the magnitude of the impact in each path.

2.2.1. Frequency Domain Analysis. Equation (1) can be simplified into (2) when you drop the effect of sound. The simplified equation is a matrix inversion method that can predict delivered load using the frequency response of the housing structure. The matrix inversion method considers the noise between different excited force vibrations by including offdiagonal elements.

$$
P_{t}(\omega)=\sum_{i=1}^{n} \operatorname{VTF}_{i}(\omega) \cdot \mathbf{F}_{i}(\omega) .
$$

Therefore, this study uses (2) for contribution in each path in the frequency domain, and it can predict the contribution of the load in each path at different frequency by multiplying the VTF (vibration transfer function) defined by the frequency response function of the structural force in each path between the experimentally obtained shock acceleration and excited force vibration.

The FRFs obtained through the modal impact experiments are used in this study. This involves employing a matrix inversion method that uses the vibration characteristics that occur during the operation of the transfer function and hydraulic breaker. Matrix inversions estimate the transferred load by substituting the mass (from Newton's second law of motion) with the transfer function. This method is now widely used in engineering [21]. Matrix inversion can be developed using the vibration characteristics obtained through the operational vibration experiments, as shown in (3), and by the inverse matrix of the FRF transfer function matrix.

$$
\begin{aligned}
& {\left[\begin{array}{c}
\mathbf{F}_{1} \\
\vdots \\
\mathbf{F}_{N}
\end{array}\right]=\left[\begin{array}{ccc}
\mathbf{H}_{1} & \cdots & \mathbf{H}_{1 N} \\
\vdots & \ddots & \vdots \\
\mathbf{H}_{M 1} & \cdots & \mathbf{H}_{M N}
\end{array}\right] \cdot\left\{\begin{array}{c}
\ddot{x}_{1} \\
\vdots \\
\ddot{x}_{M}
\end{array}\right\},} \\
& {\left[\begin{array}{c}
\mathbf{F}_{1} \\
\vdots \\
\mathbf{F}_{N}
\end{array}\right]=\left[\begin{array}{ccc}
\mathbf{H}_{1} & \cdots & \mathbf{H}_{1 N} \\
\vdots & \ddots & \vdots \\
\mathbf{H}_{M 1} & \cdots & \mathbf{H}_{M N}
\end{array}\right]^{-1} \cdot\left\{\begin{array}{c}
\ddot{x}_{1} \\
\vdots \\
\ddot{x}_{M}
\end{array}\right\} .}
\end{aligned}
$$

Herein, $\left[\mathbf{F}_{N}\right]$ is the excitation force and $\left[\mathbf{H}_{M N}\right]$ is a $M \times N$ transfer function matrix describing the characteristics of a structure obtained through the modal impact experiments. Therefore, the experimental measurement is necessary in order to use the matrix inversion method through TPA. The TPA can predict the loads based on the reference measurement point and response measurement point by 


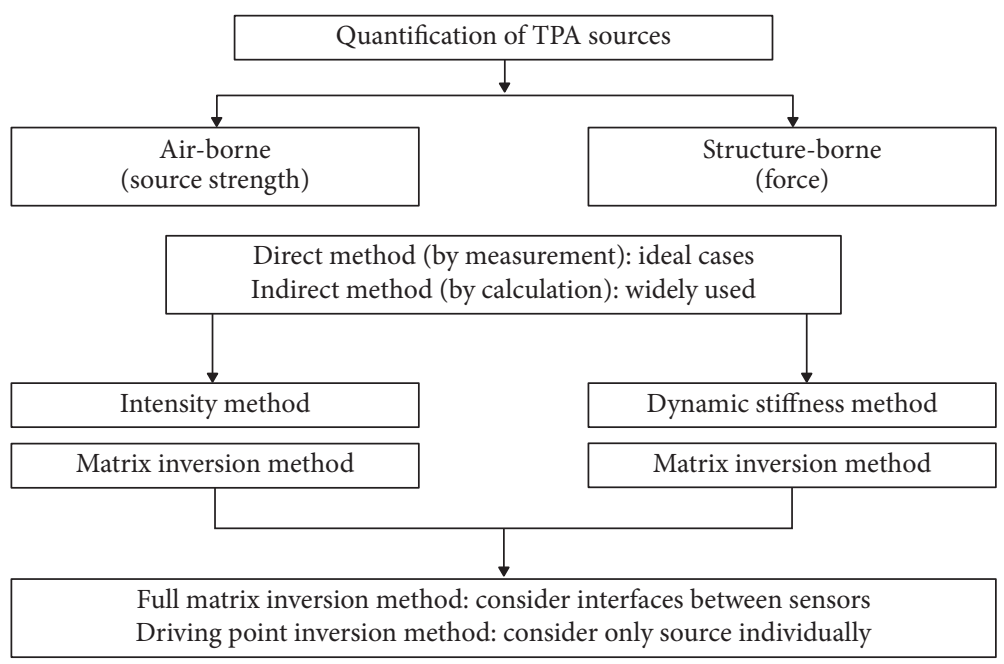

(a)

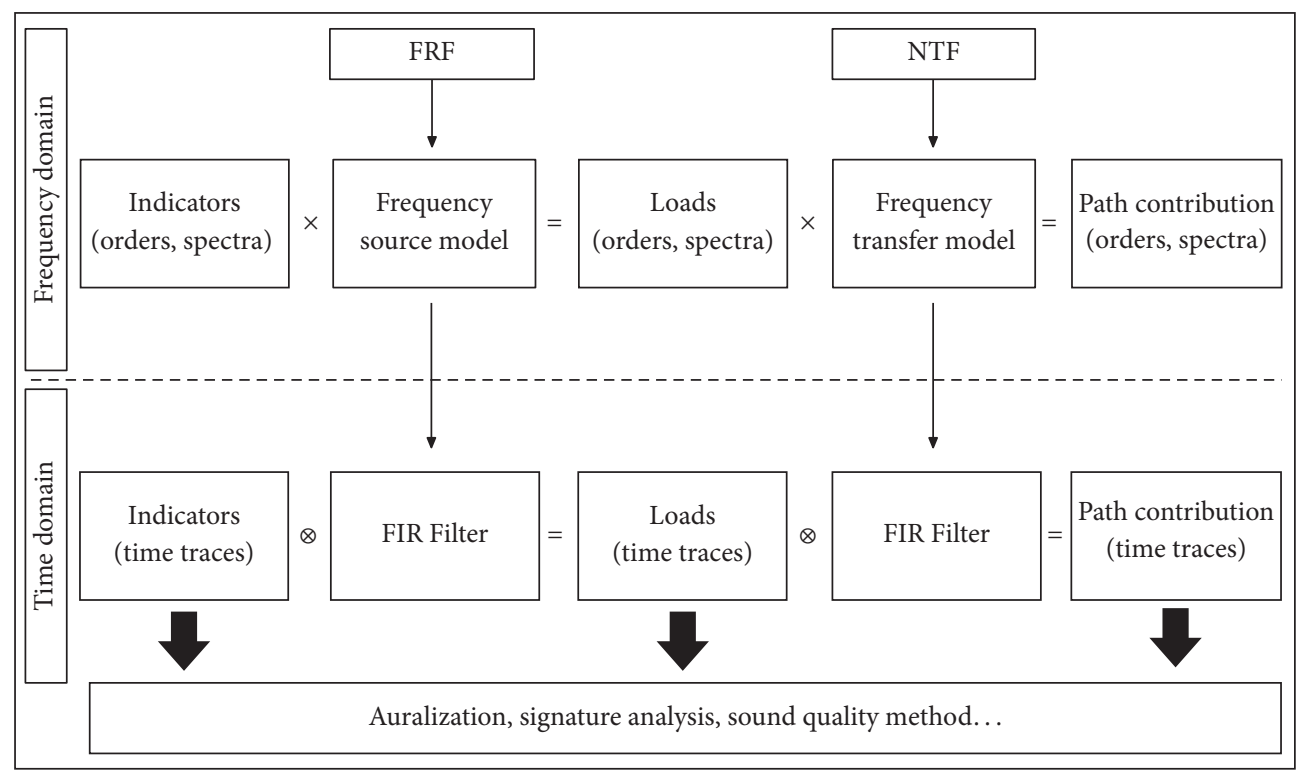

(b)

FIGURE 5: Transfer path analysis techniques: (a) process for quantifying TPA sources (Hwang et al. [23]), (b) signal processing for the time and frequency domains for TPA [24].

using singular value decomposition (SVD) and principal component analysis (PCA) [26].

2.2.2. Time Domain Analysis. Figure 5(b) compares analyses in the time and frequency domains [27]. The analyses in both domains use the same TPA method. However, the section where multiplication is applied in the frequency domain instead is applied by using the convolution integral within the time domain. In addition, the frequency domain analysis uses noise source data analyzed by order and spectrum analysis, whereas the time domain analysis uses time trace data. Convolution is used to obtain the output signal, $y(t)$, about the input signal, $x(t)$, by using the impulse response, $h(t)$, within the linear time-invariant system. In a continuous system, this is called the convolution integral and it is expressed as

$$
y(t)=x(t) \cdot h(t)=\int x(\tau) h(t-\tau) d \tau,
$$

where $h(t-\tau)$ is the impulse function in the continuous system. It is defined as the convolution sum in a discrete system as expressed by

$$
y[n]=x[n] \cdot h[n]=\sum_{k=-\infty}^{\infty} x[k] h[n-k],
$$

where $y[n]$ is the discrete output signal, $x[n]$ is the discrete input signal, and $h[n]$ is the impulse response of the discrete 
TABLE 1: Parameters for vibration experiments and operating conditions for the excavator.

\begin{tabular}{lcc}
\hline Items & Parameters & Value \\
\hline \multirow{2}{*}{ Tracking } & Measurement method & Time trace \\
& Duration & $30 \mathrm{~s}$ \\
\multirow{2}{*}{ Acquisition } & Increment & $0.5 \mathrm{~s}$ \\
& Bandwidth & $6400 \mathrm{~Hz}$ \\
Excavator & Resolution & $12.5 \mathrm{~Hz}$ \\
& Weight & $36 \mathrm{ton}$ \\
Hydraulic system & Engine & $1700 \mathrm{rpm}$ \\
& Flow rate & $200 \mathrm{lpm}$ \\
& Working pressure & $160 \mathrm{bar}$ \\
\hline
\end{tabular}

system. The function $h[n-k]$ represents the discrete unitimpulse function, which also includes the time invariance. Additionally, $\tau$ and $k$ are arbitrary variables.

2.3. Vibration Experiment Setup. In this study, we clarified the characteristics of a hydraulic breaker and estimated the impact loads delivered to the housing quantitatively. The vibrations occurring during striking were measured by attaching an acceleration sensor (Figure 6(a)) to a position that represented the shape of the hydraulic breaker properly. The sensor was a three-axis accelerometer with 90 available channels designed for high-impact environments. Data acquisition and analysis were managed by a SCADAS Mobile DAQ system with Test.lab software from Siemens for overall experimental control. Table 1 show the conditions for the vibration experiments and the operational conditions of the excavator used in the experiments.

The hydraulic breaker operates by converting the energies of the hydraulic pressure and nitrogen gas into the kinetic energy of the striking pistons. The kinetic energy is then delivered to the rock via the chisel, thereby breaking it. The hydraulic breaker in this study strikes the steel plate (Figure 6(b)) to create uniform impact loads. The setup and adjustments ensured the repeatability and reproducibility of the experiment and minimized variations in the impact loads caused by the compressive strength of the rock. The setup also excluded any effects caused by the inhomogeneity and anisotropy of the rock.

Higher impact loads were expected during the striking of the steel plates than during actual bedrock striking. This was because the energy that would be used to break the bedrock was expected to be delivered to the housing in the form of a reaction force (in addition to the energy dissipated by vibrations and heat). Further experiments using actual bedrock are required to explore this further.

Figure 7 shows results measured by sensor number 14 during operation: vibration impact signals in the $z$-direction, which was the main striking direction, are shown with respect to time. Table 2 lists the analysis results for the signals during the striking.

2.4. Modal Impact Experiments. Figure 8(a) gives the results of modal impact testing for the analysis of the hydraulic
TABLE 2: Results of vibration and modal impact experiments.

\begin{tabular}{lcc}
\hline Exp. type & Description & Value \\
\hline \multirow{2}{*}{ Vibration } & Max. acceleration & $104.9 \mathrm{~g}$ \\
& Impulse period & $3.44 \mathrm{~Hz}$ \\
& Decay time & $0.23 \mathrm{~s}$ \\
Modal impact & Blow per min & $206 \mathrm{bpm}$ \\
\hline & Mode shapes & Value \\
\hline & 1st $X$-axis bending & $75 \mathrm{~Hz}$ \\
& 2nd $Y$-axis bending & $115 \mathrm{~Hz}$ \\
& 3rd $Y$-axis bending & $174 \mathrm{~Hz}$ \\
& High $Y$-axis bending $+X$-axis torsion & $425 \mathrm{~Hz}$ \\
\hline
\end{tabular}

breaker's characteristics and native mode. Modal impact testing can obtain the modal parameters of a structure, which are the eigenvalue (natural frequency and damping) and eigenvectors (mode shapes) of the dynamic system for the vibratory structure [28, 29].

Modal impact experiments were used to set the position of excitation for obtaining the FRFs along the $y$-directions on the bottom end of the hydraulic breaker (Figure $8(\mathrm{a})$ ). The FRF matrix, which can be obtained through modal impact testing, provides the mass matrix and strength matrix of the structure, but also the damping matrix, thereby enabling the derivation of characteristics that consider the dynamic system $[19,29]$. Examining the major modal characteristics of the hydraulic breaker (Figure 8(b)) showed that the bending mode often occurred in low-frequency bands. This was attributed to the breaker's scale and its overall shape. Table 2 shows the respective mode shapes and their corresponding frequencies.

2.5. Impact Energy Measurement of the Hydraulic Breaker. The quantitative estimation of the impact loads delivered to the housing through each transfer path requires quantitative information of the striking force at the chisel. This striking force can be used as the datum value for validating the TPA calculation and is also defined as the physical quantity required for verifying the validity of the calculation results. The striking force at the chisel can be calculated from the striking energy measured using the strain gauge [30].

The striking energy of the hydraulic breaker can be calculated by measuring the deformation of the strain gauge attached to the chisel. Figure 9(a) outlines the strain gauges' attachment. The energy of a single strike performed by the hydraulic breaker, calculated using (6), was derived from the deformation measured by the strain gauge and the elastic strain energy [30].

$$
E_{i}=\frac{\mathrm{CF}^{2}}{A_{c} \cdot \sqrt{E_{c} \cdot \rho_{c}}} \int_{t_{1}}^{t} \varepsilon_{i}^{2} d t,
$$

where $E_{i}$ is the striking energy generated by a single strike of the chisel, $A_{c}$ is the cross-sectional area of the chisel, $E_{c}$ is Young's modulus of the chisel, $\rho_{c}$ is the density of the chisel, $\mathrm{CF}$ is the calibration factor in static calibration, and $\varepsilon_{i}$ is the deformation of the chisel. 

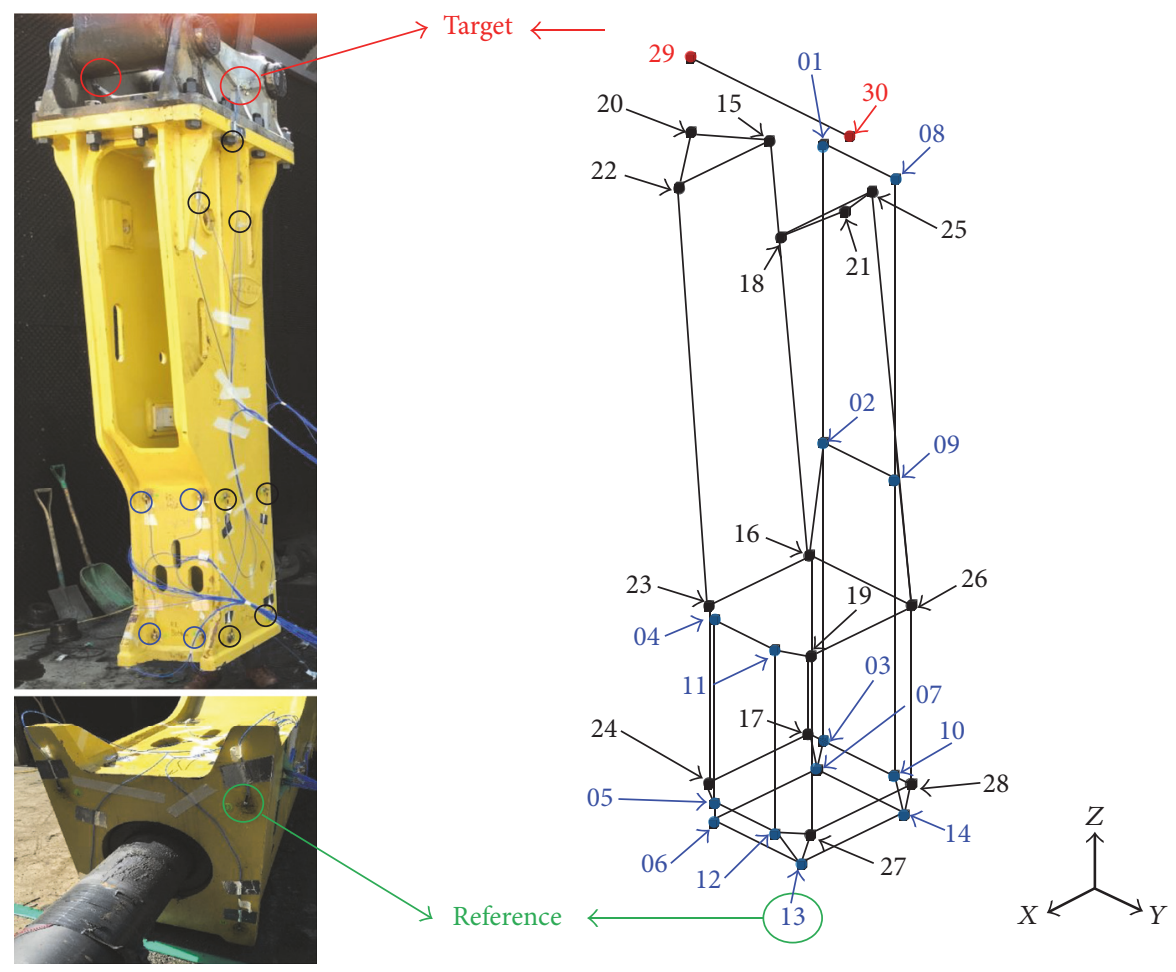

(a)

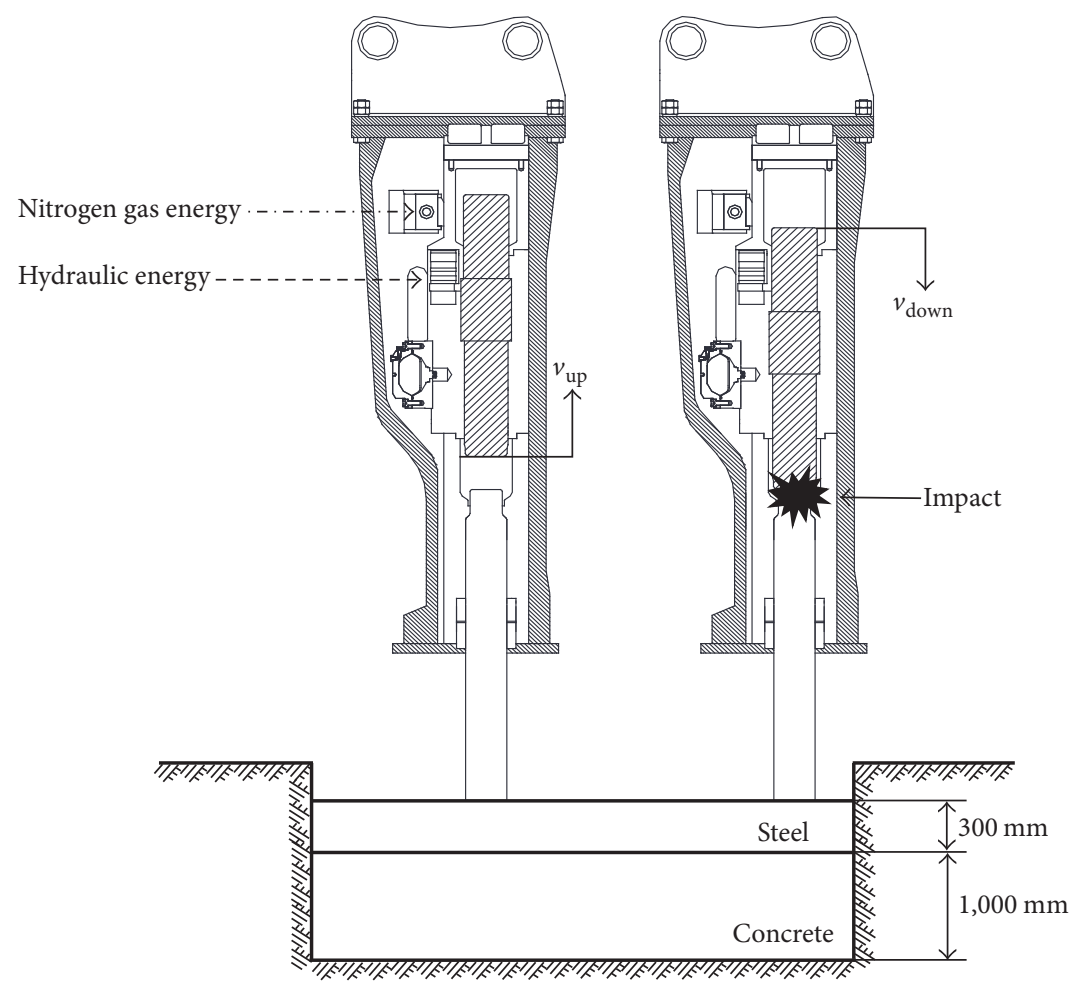

(b)

FIGURE 6: Vibration experiment setup: (a) installation positions of triaxial accelerometers, (b) mechanism of the hydraulic breaker and vibration test conditions. 


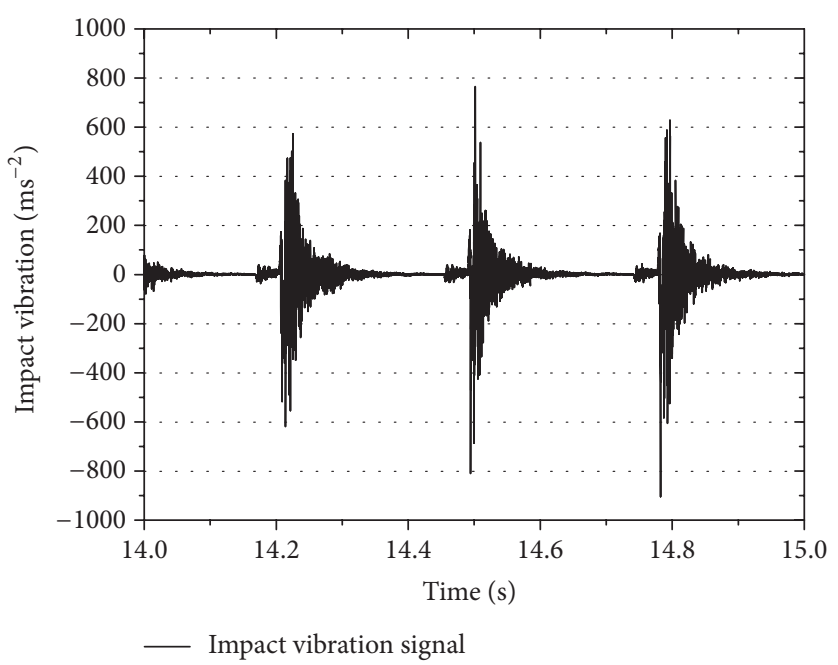

FIGURE 7: Measured vibration signal from the operating hydraulic breaker.

TABLE 3: Results of impact energy measurement.

\begin{tabular}{lccc}
\hline Items & Description & Unit & Value \\
\hline \multirow{2}{*}{ Chisel properties } & Young's modulus & $\mathrm{kg}_{\mathrm{f}} / \mathrm{m}^{2}$ & $2.10 e+10$ \\
& Cross section area & $\mathrm{m}^{2}$ & $0.0213 \mathrm{~m}^{2}$ \\
Impact energy & Impact energy of chisel & $\mathrm{J}$ & 4659.68 \\
& Strain rate & & $8.42 e-04$ \\
Impact force & Impact force of chisel & $\mathrm{kN}$ & 3693 \\
\hline
\end{tabular}

Figure 9(b) shows the measured impact strain of the deformation caused by the shock wave of the chisel striking. The striking energy calculated by the strain gauge, the maximum deformation, and the physical properties of the chisel are listed in Table 3. The striking force of the chisel was calculated based on the stress-strain relation by (7).

$$
F_{\text {impulse }}=\left(E_{c} \varepsilon_{i}\right) \times A_{c},
$$

where $F_{\text {impulse }}$ is the striking force generated by the chisel and $E_{c}$ is Young's modulus of the chisel. The impact energy and striking force during the striking action of the hydraulic breaker are given in Table 3.

The efficiency of hydraulic breaker, $\eta_{h}$, can be defined as follows with supply pressure and volumetric flow rate as an input and the striking energy and frequency as an output:

$$
\eta_{h}=\frac{e_{i} \cdot f_{i}}{\mathrm{Q}\left(P_{s}-P_{r}\right)},
$$

where $Q$ is volumetric flow rate, $P_{s}$ is supply pressure, $P_{r}$ is output pressure, $e_{i}$ is piston's energy, and $f_{i}$ is the striking frequency. If we assume piston's energy $e_{i}$ is equal to the chisel's energy $E_{i}$, the impact energy efficiency of the hydraulic breaker can be defined as follows.

$$
\eta_{h}=\frac{E_{i} \cdot f_{i}}{Q\left(P_{s}-P_{r}\right)} .
$$

Also, it is decided that the energy loss from the chisel can be predicted per input condition using (9).
2.6. TPA of the Hydraulic Breaker. TPA performs calculations by using the characteristics of the impact vibrations that occur during operation and the transfer function matrix $\left[\mathbf{H}_{M N}\right]$ obtained by the excitation of the transfer path. The path is a medium that contributes to the load transfer between the subject of the striking (the main body, namely, the excitation source) and the structure being struck. The calculation of the load transferred through the medium is possible only when the native characteristics of the greatest contributing medium are known. Therefore, each path that contributes to the load transfer of the hydraulic breaker was selected (Figure 10).

Path selection determined that the isolation pad, which was expected to show a high contribution to the impact load transfer, is within the major transfer path. This is because the hydraulic breaker's main body, namely, the excitation source and housing, are coupled by the isolation pad. In addition, the position of each isolation pad represents a position of excitation, which is also required for TPA. An excitation jig identical in shape to the isolation pad was manufactured for conducting the three-way excitations for each excitation position to investigate the transfer path (Figure 10).

\section{Results and Discussion}

By using TPA, the impact load was calculated by direction and by part during the operation of the hydraulic breaker. Although the main load of the hydraulic breaker was applied in the vertical direction, the impact loads were delivered to the housing due to pitch, roll, and yaw motions, which arose from vibrations of the main body caused by the striking action. Therefore, the impact loads delivered to the housing from all directions (i.e., $x$-, $y$-, and $z$-direction) were considered (Figure 3).

Figure 11(a) shows the analysis results in the frequency domain, indicating the contribution of the impact loads delivered to the housing through each isolation pad. The results indicate that the bottom and middle sections of the 

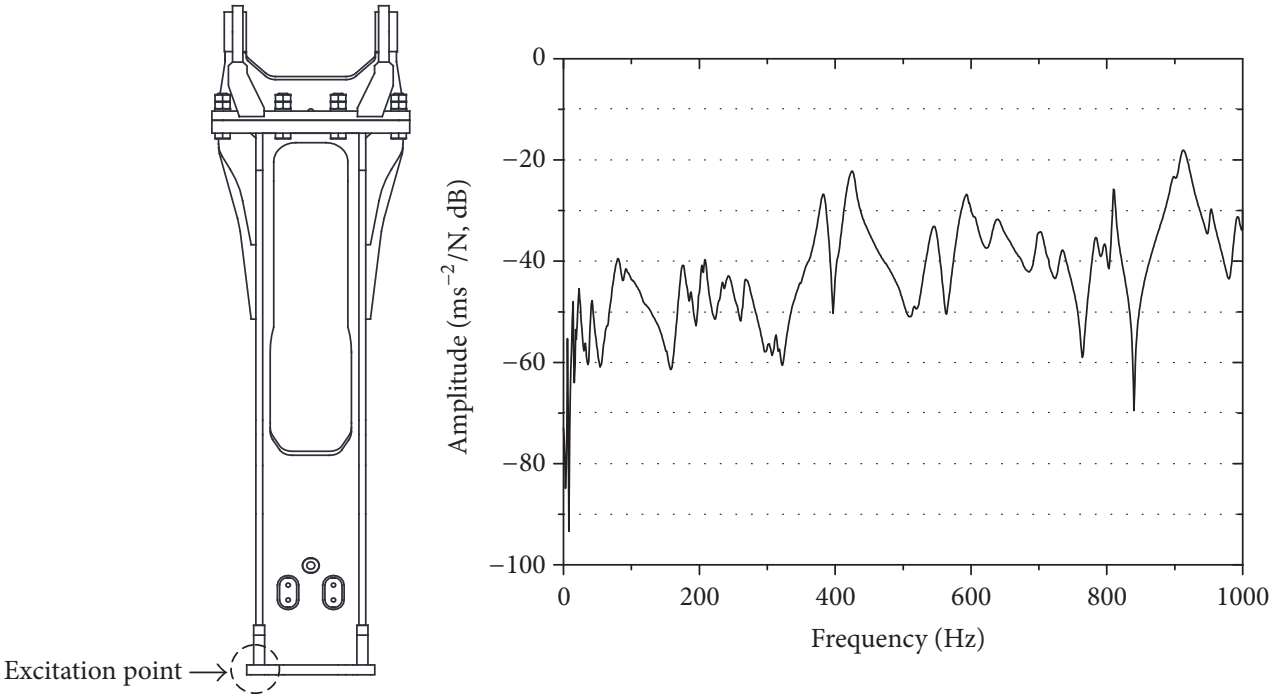

(a)

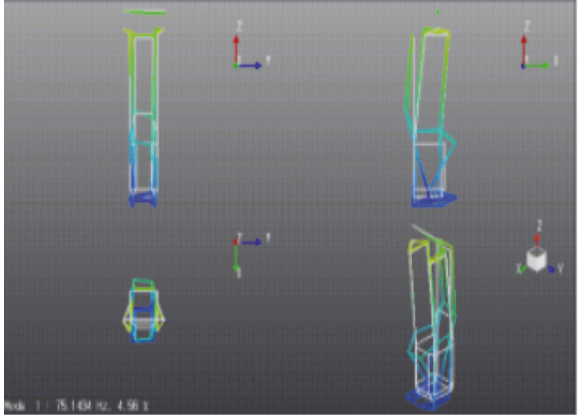

1st $75 \mathrm{~Hz}$

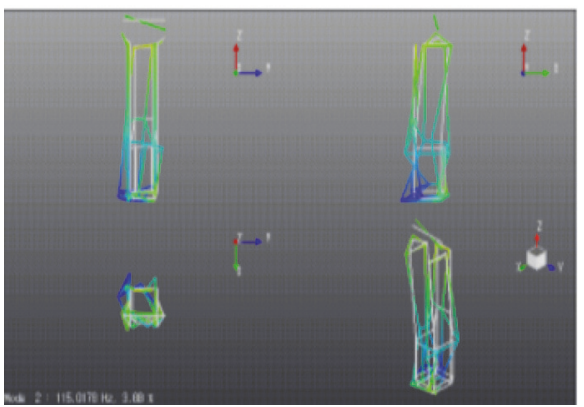

2nd $115 \mathrm{~Hz}$

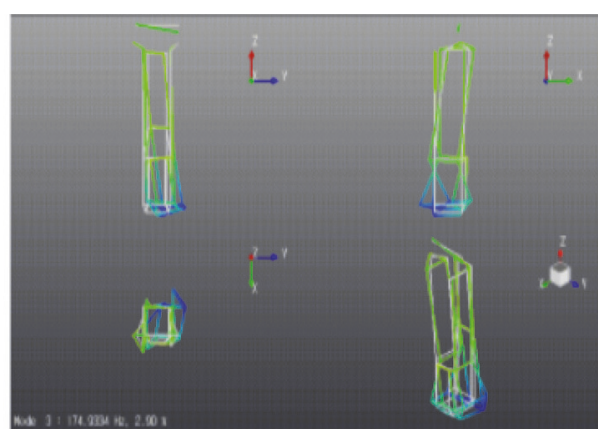

$3 \mathrm{rd} 174 \mathrm{~Hz}$

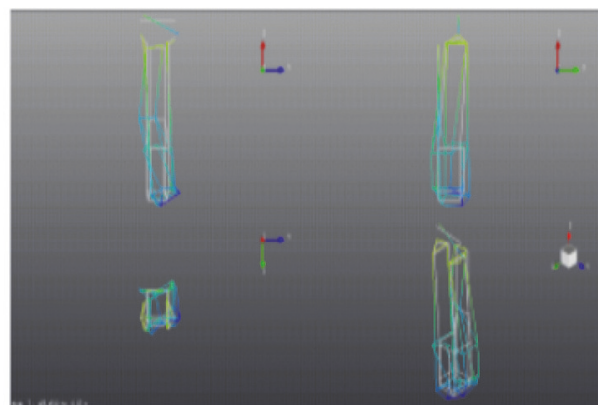

High $425 \mathrm{~Hz}$

(b)

FIGURE 8: Modal impact experiments: (a) measured frequency response function, (b) mode shapes of the hydraulic breaker. 


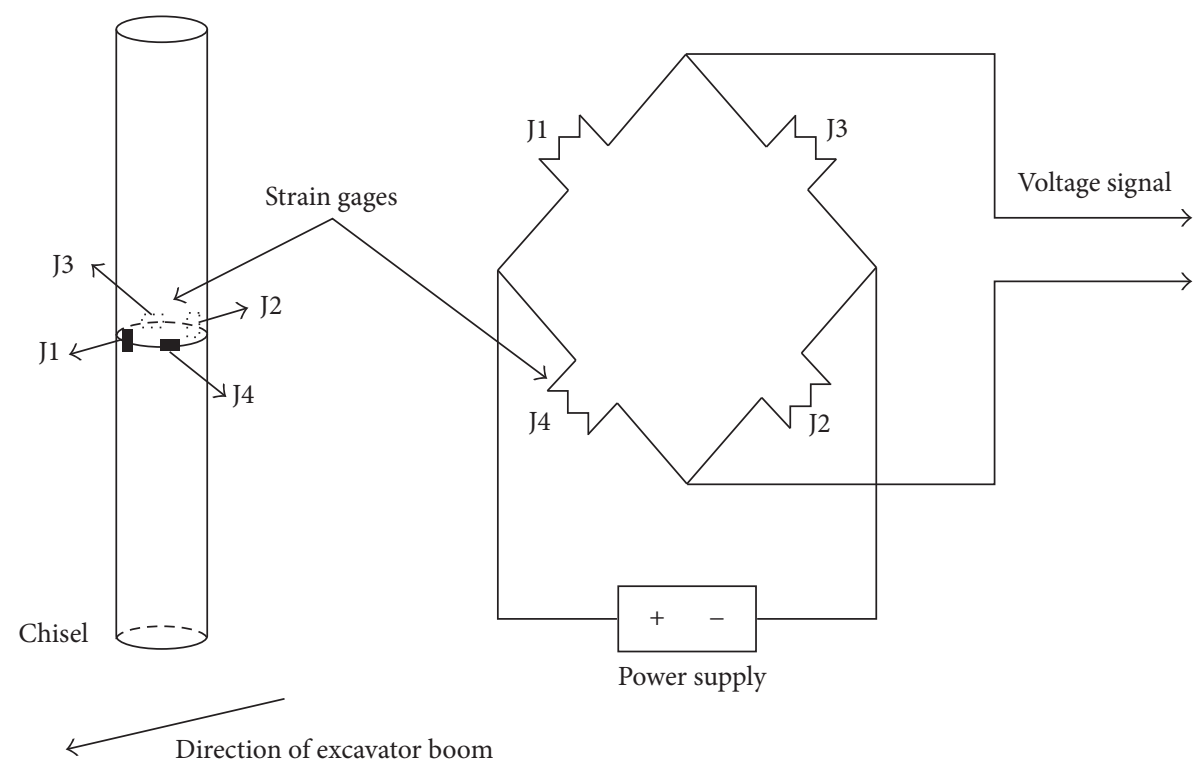

(a)

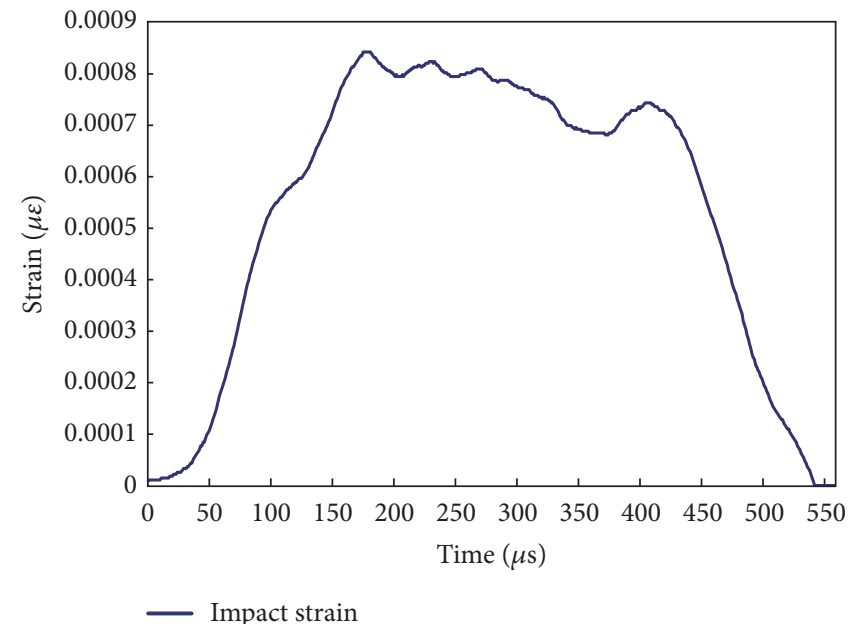

(b)

FIGURE 9: Impact energy measurement: (a) setup of the strain gauges, (b) shock wave profile of impact energy strain.

hydraulic breaker generated high-impact loads. Figure 11(b) presents the vibration transfer function (VTF) map that shows the contribution of the frequency domains to the load transfer. The VTF results indicate that the maximum load was generated from the low-frequency band below approximately $400 \mathrm{~Hz}$. Impact loads delivered to the housing at high-frequency bands above $2,000 \mathrm{~Hz}$ had little effect.

Figure 12 shows the vector contribution plot of the loads in frequency between 20 and $400 \mathrm{~Hz}$, which is the frequency where maximum loads occur in a hydraulic breaker. The red illustrates the vector of the total impact load, the black signifies the measured impact load vector, and the blue signifies the vector of the partial impact load. The analysis shows that the total vector and measured vector lie in same direction and in similar magnitude, validating the credibility of the experiment. Also, the influence of the total vector and each partial vectors on the impact load can be checked.

This study extracts the magnitude and direction of the impact load delivered to the housing of a hydraulic breaker in order to maximize the safety and endurance of the housing structure. Depending on the frequency analysis method used, the results of impact load may vary. In other words, the results of the analysis will change if the phase relationship is considered.

Figure 13 shows the result of time domain analysis that portrays the magnitude and direction of the impact load delivered to the housing in each path. The analysis used the real value instead of the amplitude of the impact load so the magnitude of the load in each direction can be verified. As a result, the quantifiable prediction of impact load from the 


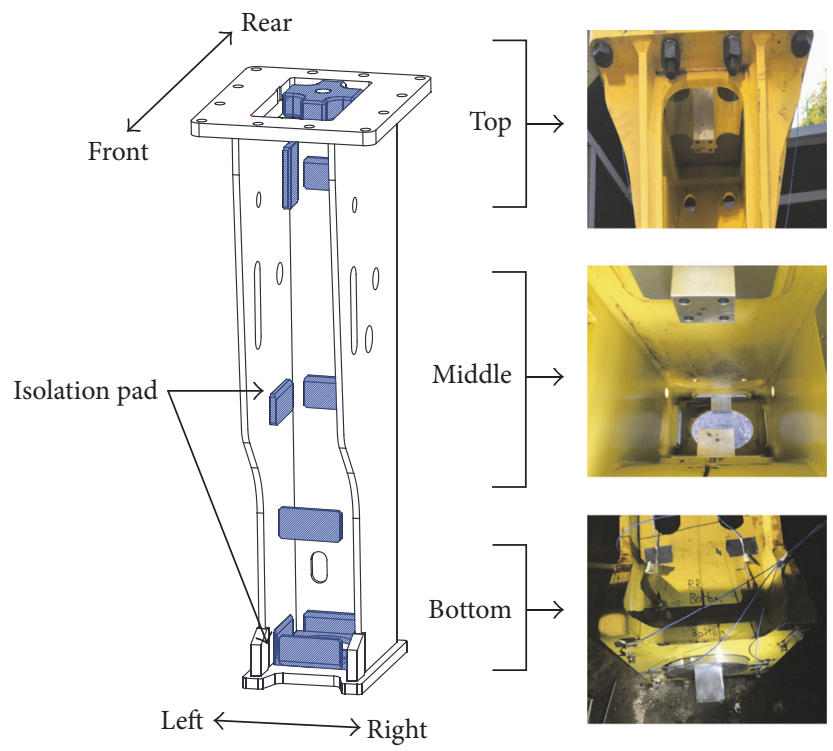

FIgURE 10: Position of the isolation pad in the hydraulic breaker and triaxial excitation jig for FRF acquisition.

chisel to the housing through a time domain TPA became possible. Table 4 lists the results of TPA on the impact loads delivered to the housing via the isolation pad during striking.

The impact load obtained by TPA was $2,853.2 \mathrm{kN}$, whereas that from the striking force measured by the strain gauge was $3693 \mathrm{kN}$, a difference of $22.6 \%$. This means that the reaction force generated during the striking action of the chisel was damped by the isolation pad and was delivered to the housing instead. Therefore, the applicability of TPA to a structure with impact loads and vibrations was confirmed. This approach considers the energy loss caused by the noise, vibration, and heat occurring during the chisel's strikes and reflects the assumption that such energy loss is instead delivered to the housing in the form of a reaction force. Assessing the reliability of the TPA approach requires further work that introduces computer-aided engineering to the investigation of the load transfer through the isolation pad as well as additional physical tests on the isolation pad.

Furthermore, an additional study based on the present measurements and evaluation of the loads might lead to a new method for estimating the dynamic damping factor of various isolation pads. This is because isolation pads reduce the impact loads and vibrations in various kinds of mechanical equipment, including hydraulic breakers, and thus are closely related to the durability and performance of mechanical equipment. The impact loads for each direction and component obtained from the present results can be used as input values for subsequent numerical analyses of the hydraulic breaker.

In order to create an effective design of a hydraulic breaker housing, the impact load should reflect real operational condition and be applied on the actual rocks. For this, an impact test needs to be carried out on rocks with different hardness. However, this study was not able to include such effects of different rock hardness. So, we expect a bit of a discrepancy between the impact load on a steel plate and a real rock, which is the limitation of this study that needs to be overcome in future studies.

Also, it is necessary to do analysis on the correlation between the impact load and each path. This is because the correlation and sensitivity between the magnitude of each load and the major paths need to be studied in order to propose an efficient design of a hydraulic breaker. The impact loads can also be used as important data for evaluating and optimizing the equipment's structural safety. Additional studies on the output striking force stemming from the pressure and flow of the hydraulic breaker, expressed as the product of the input striking force, the number of strikes, and striking energy, are expected to improve the technical performance of the equipment.

\section{Conclusions}

This study reviewed the applicability of TPA to conditions where strain gauges and load cells are difficult to use. A hydraulic breaker was tested to explore the method for quantitatively estimating the impact loads of construction machinery and attachments. The applicability of TPA was confirmed based on estimating the impact loads through operational vibration and modal impact experiments, while accounting for the impact vibrations and impact loads of the mechanical equipment. The validity of TPA for a structure with impact vibrations and impact loads was also verified by comparing the striking force of the chisel obtained by a strain gauge with the impact loads calculated by TPA.

Quantitative impact loads were calculated by TPA for different directions and parts of the housing during the striking action of the hydraulic breaker. The contribution of the impact loads in each component was confirmed by the load contribution map. The VTF map explored the frequency bands primarily used for the load transfer. At high-frequency bands above $2000 \mathrm{~Hz}$, the effect of the impact loads delivered 

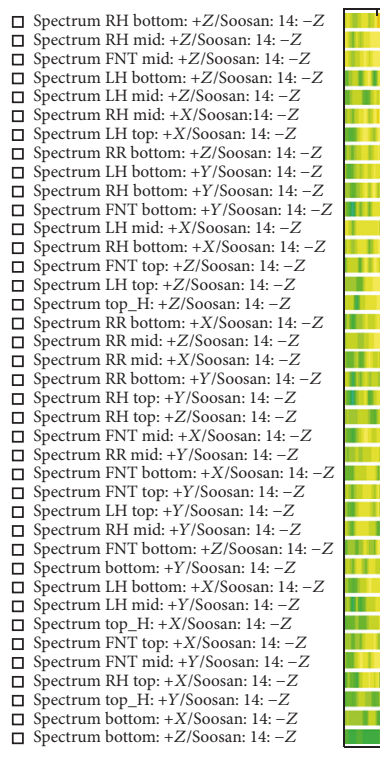

TII

\section{,}

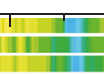

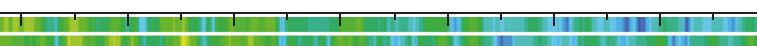

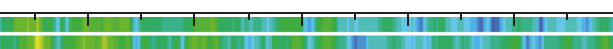

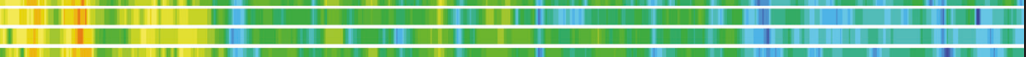

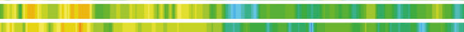

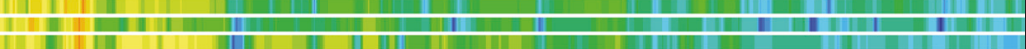

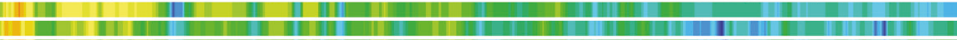
1)

III|| || || ||

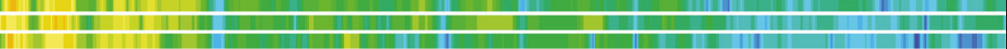

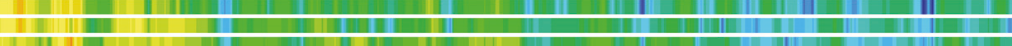

|

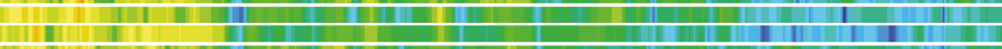

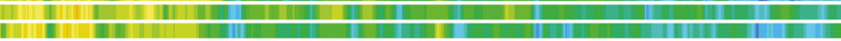

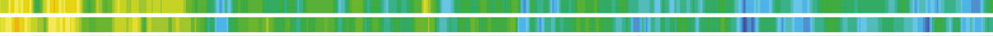

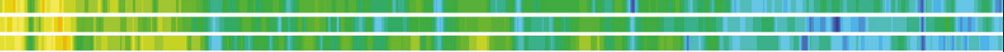

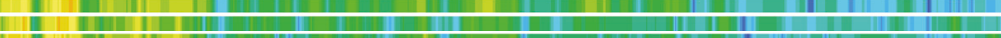

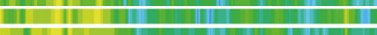

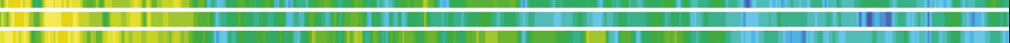

|

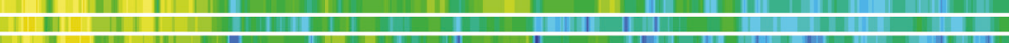

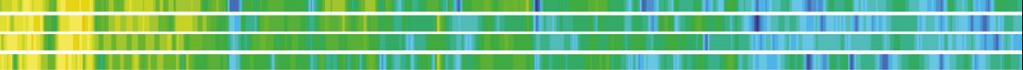

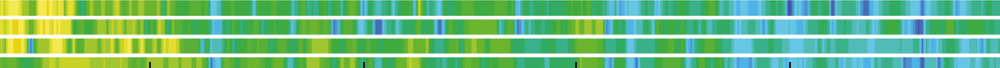

200

400

600

800

1000

$-10.00$

Linear

$(\mathrm{Hz})$

(a)

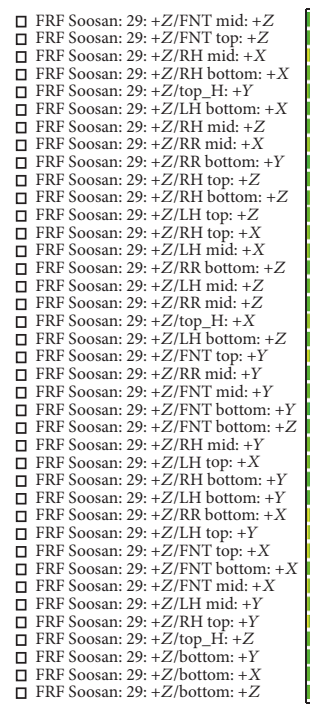

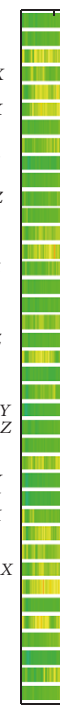

20

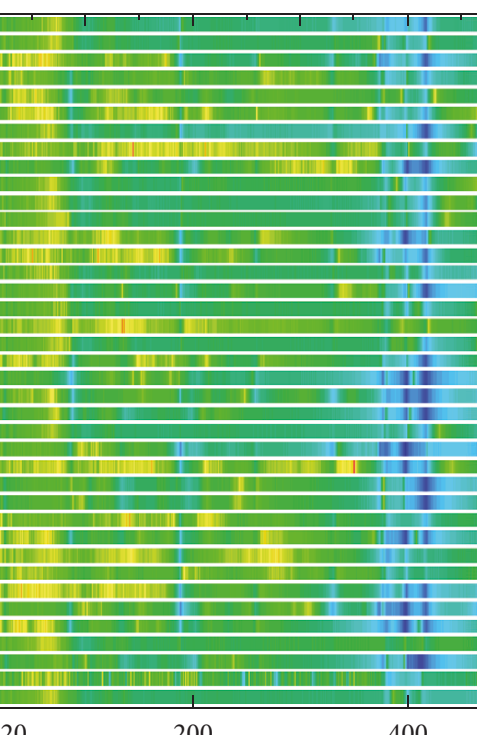

200
400
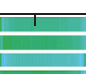

| Int

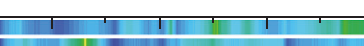




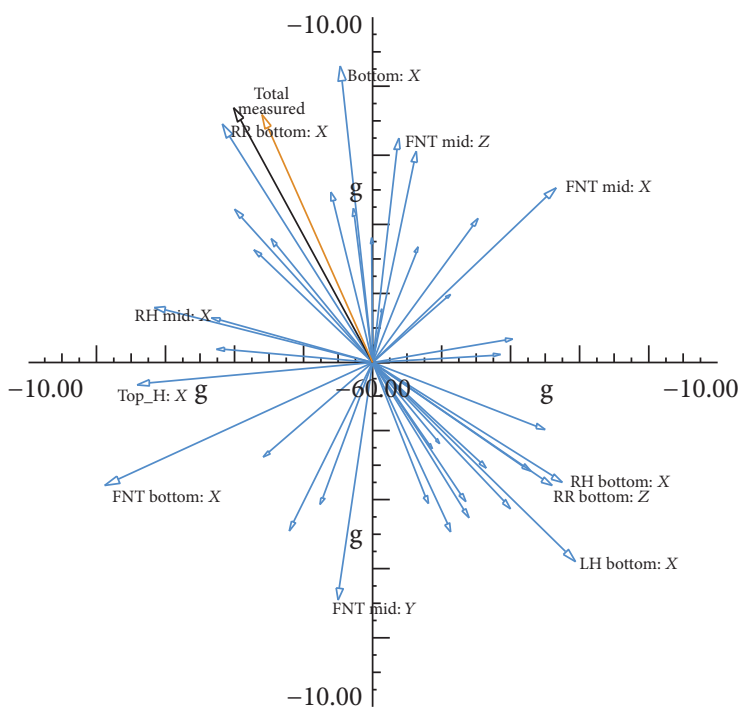

FIGURE 12: Vector contribution plot of loads in frequency between 20 and $400 \mathrm{~Hz}$.

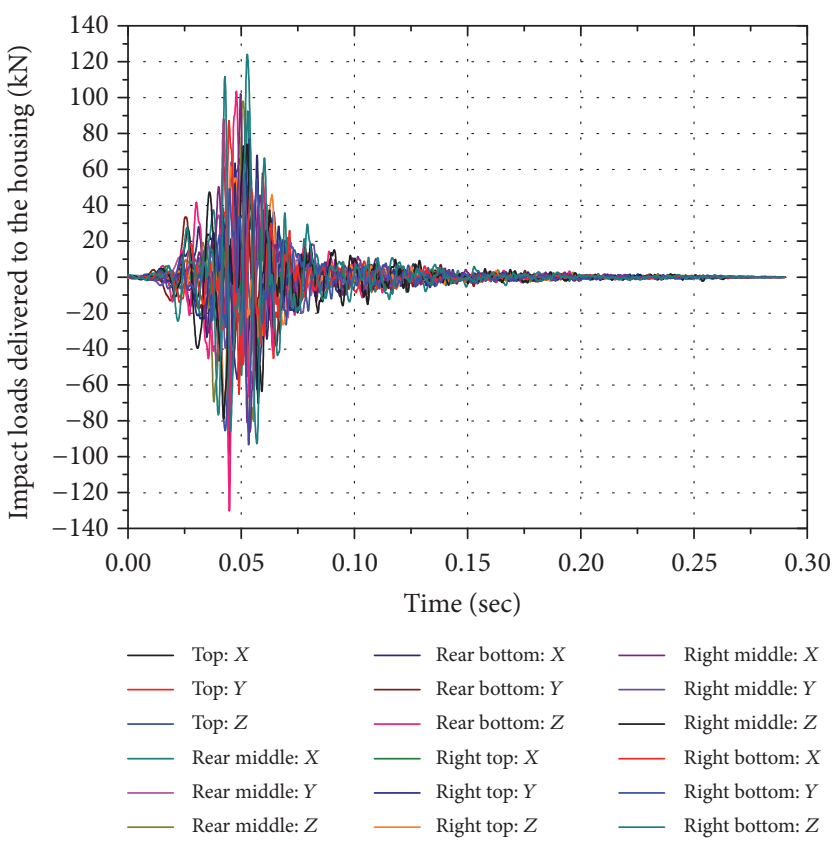

(a)

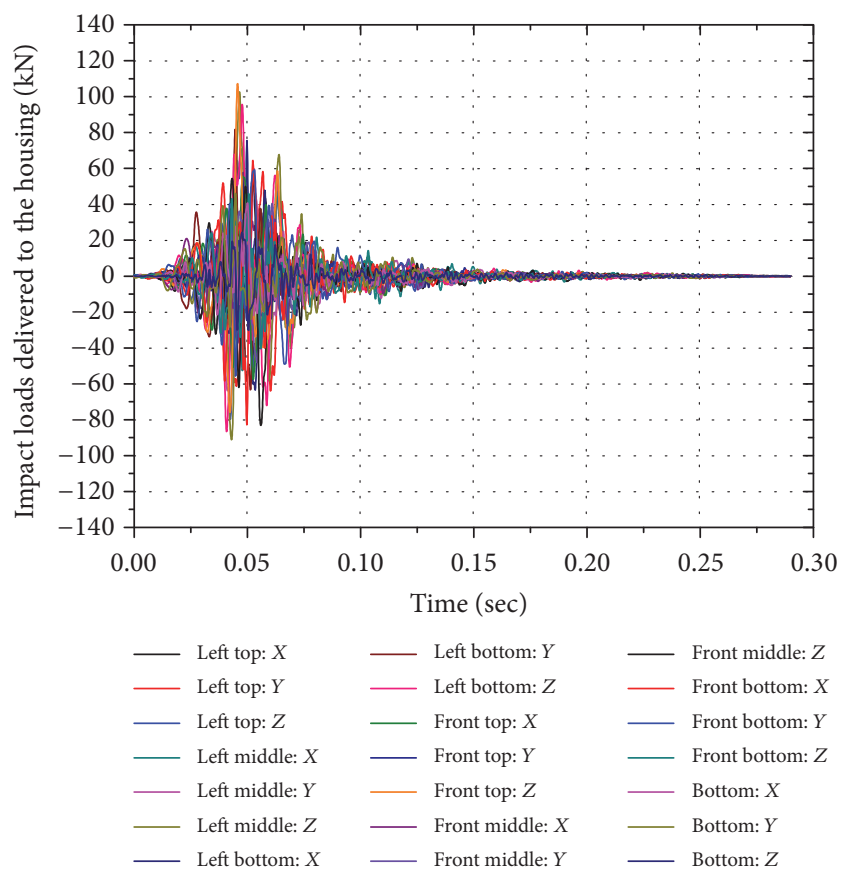

(b)

FIGURE 13: The load profile of impact on the housing in each path: (a) path numbers (1) (18), (b) path numbers (19) (39). 
TABLE 4: Contribution of impact loads in the hydraulic breaker.

\begin{tabular}{|c|c|c|c|c|}
\hline \multirow{2}{*}{ Path number } & \multirow{2}{*}{ Path } & \multirow{2}{*}{ Axis } & \multicolumn{2}{|c|}{ Force $(\mathrm{kN})$} \\
\hline & & & + direction & -direction \\
\hline (1) & & $X$ & 45.2 & 62.4 \\
\hline (2) & Top & $Y$ & 38.4 & 45.2 \\
\hline (3) & & $Z$ & 66.3 & 85.5 \\
\hline (4) & & $X$ & 92.5 & 60.6 \\
\hline (5) & Rear middle & $Y$ & 34.5 & 51.9 \\
\hline (6) & & $Z$ & 98.1 & 83.5 \\
\hline (7) & & $X$ & 67.8 & 99.1 \\
\hline (8) & Rear bottom & $Y$ & 61.7 & 95.6 \\
\hline (9) & & $Z$ & 103.5 & 130.3 \\
\hline (10) & & $X$ & 26.7 & 20.0 \\
\hline (11) & Right top & $Y$ & 77.0 & 63.8 \\
\hline (12) & & $Z$ & 61.6 & 71.8 \\
\hline (13) & & $X$ & 102.1 & 86.3 \\
\hline (14) & Right middle & $Y$ & 67.8 & 39.6 \\
\hline (15) & & $Z$ & 74.1 & 78.9 \\
\hline (16) & & $X$ & 87.1 & 65.2 \\
\hline (17) & Right bottom & $Y$ & 54.7 & 93.4 \\
\hline (18) & & $Z$ & 124.1 & 92.8 \\
\hline (19) & & $X$ & 43.4 & 46.0 \\
\hline (20) & Left top & $Y$ & 58.2 & 64.0 \\
\hline$(21)$ & & $Z$ & 70.9 & 79.6 \\
\hline$(22)$ & & $X$ & 55.1 & 52.6 \\
\hline (23) & Left middle & $Y$ & 59.7 & 63.8 \\
\hline (24) & & $Z$ & 102.6 & 91.1 \\
\hline (25) & & $X$ & 75.4 & 63.5 \\
\hline$(26)$ & Left bottom & $Y$ & 81.9 & 63.3 \\
\hline (27) & & $Z$ & 95.6 & 86.6 \\
\hline (28) & & $X$ & 55.5 & 57.4 \\
\hline (29) & Front top & $Y$ & 20.8 & 29.3 \\
\hline$(30)$ & & $Z$ & 107.2 & 75.8 \\
\hline (31) & & $X$ & 31.6 & 37.2 \\
\hline$(32)$ & Front middle & $Y$ & 40.3 & 48.0 \\
\hline (33) & & $Z$ & 56.9 & 83.1 \\
\hline (34) & & $X$ & 64.5 & 82.7 \\
\hline (35) & Front bottom & $Y$ & 59.3 & 55.7 \\
\hline$(36)$ & & $Z$ & 45.9 & 40.4 \\
\hline$(37)$ & & $X$ & 40.7 & 21.9 \\
\hline (38) & Bottom & $Y$ & 46.2 & 28.4 \\
\hline (39) & & $Z$ & 24.4 & 30.1 \\
\hline
\end{tabular}

to the housing was minor. To ensure the reliability of the TPA approach used here, additional comparative analyses of the impact loads delivered to the hydraulic breaker's housing are required through conducting various experiments including those using strain gauges and load cells.

\section{Conflicts of Interest}

The authors declare that they have no conflicts of interest.

\section{References}

[1] A. Giuffrida and D. Laforgia, "Modelling and simulation of a hydraulic breaker," International Journal of Fluid Power, vol. 6 , no. 2, pp. 47-56, 2005.

[2] K. S. Kwak and H. W. Chang, "Performance optimization of a fully hydraulic breaker using Taguchi method," Journal of Drive and Control, vol. 5, pp. 41-48, 2008.

[3] A. Ficarella, A. Giuffrida, and D. Laforgia, "Numerical investigations on the working cycle of a hydraulic breaker: Off-design performance and influence of design parameters," International Journal of Fluid Power, vol. 7, no. 3, pp. 41-50, 2006.

[4] A. Ficarella, A. Giuffrida, and D. Laforgia, "Investigation on the impact energy of a hydraulic breaker," SAE Technical Paper 2007-01-4229, 2007.

[5] A. Ficarella, A. Giuffrida, and D. Laforgia, "The effects of distributor and striking mass on the performance of a hydraulic impact machine," SAE Technical Paper 2008-01-2679, 2008.

[6] S. H. Lee, C. S. Han, and C. S. Song, "A study on the performance improvement of a high efficiency hydraulic breaker," Journal of the Korean Society of Tribologists and Lubrication Engineers, vol. 19, no. 2, pp. 59-64, 2003.

[7] B. S Kim, M. G. Kim, D. W. Byun, S. M. Lee, and S. H. Lee, "A study on the structure improvement of bracket housing for structural noise and vibration reduction in hydraulic," Journal of the Korean Society for Precision Engineering, vol. 23, no. 11, pp. 108-115, 2006.

[8] G.-B. Park, C.-H. Park, Y. S. Park, and D.-H. Choi, "Optimal design for minimizing weight of housing of hydraulic breaker," Transactions of the Korean Society of Mechanical Engineers A, vol. 35, no. 2, pp. 207-212, 2011.

[9] K. G. Sundin and M. Jonsson, "A stiff and compact impactforce transducer based on strain measurement," Experimental Mechanics, vol. 25, no. 1, pp. 48-53, 1985.

[10] W. E. Baker and R. C. Dove, "Measurement of internal strains in a bar subjected to longitudinal impact-technique developed by authors for the study of strain distribution inside bar makes use of commercially available strain gages," Experimental Mechanics, vol. 2, no. 10, pp. 307-311, 1962.

[11] S.-I. Suzuki, "Measured dynamic-load factors of cantilever beams, frame structures and rings subjected to impulsive loads-experimental results indicate that dynamic-load factors are influenced substantially by solid viscosities and frequency," Experimental Mechanics, vol. 11, no. 2, pp. 76-81, 1971.

[12] J. Knapp, E. Altmann, J. Niemann, and K.-D. Werner, "Measurement of shock events by means of strain gauges and accelerometers," Measurement, vol. 24, no. 2, pp. 87-96, 1998.

[13] C. J. Shepherd, G. J. Appleby-Thomas, J. M. Wilgeroth, P. J. Hazell, and D. F. Allsop, "On the response of ballistic soap to one-dimensional shock loading," International Journal of Impact Engineering, vol. 38, no. 12, pp. 981-988, 2011.

[14] X. Xue, T. Ren, and W. Zhang, "Analysis of fatigue damage character of soils under impact load," Journal of Vibration and Control, vol. 19, no. 11, pp. 1728-1737, 2013.

[15] K. Hashiba, K. Fukui, Y. Z. Liang, M. Koizumi, and T. Matsuda, "Force-penetration curves of a button bit generated during impact penetration into rock," International Journal of Impact Engineering, vol. 85, pp. 45-56, 2015.

[16] J. Zhang, S. L. Guo, Z. S. Wu, and Q. Q. Zhang, "Structural identification and damage detection through long-gauge strain measurements," Engineering Structures, vol. 99, pp. 173-183, 2015. 
[17] S. J. Kim and S. K. Lee, "Prediction of interior noise by excitation force of the powertrain based on hybrid transfer path analysis," International Journal of Automotive Technology, vol. 9, no. 5, pp. 577-583, 2008.

[18] O. Guasch, C. García, J. Jové, and P. Artís, "Experimental validation of the direct transmissibility approach to classical transfer path analysis on a mechanical setup," Mechanical Systems and Signal Processing, vol. 37, no. 1-2, pp. 353-369, 2013.

[19] M. V. Van Der Seijs, D. De Klerk, and D. J. Rixen, "General framework for transfer path analysis: History, theory and classification of techniques," Mechanical Systems and Signal Processing, vol. 68-69, pp. 217-244, 2016.

[20] B. Sakhaei and M. Durali, "Vibration transfer path analysis and path ranking for NVH optimization of a vehicle interior," Shock \& Vibration, vol. 2014, Article ID 697450, 5 pages, 2014.

[21] P. Gajdatsy, K. Janssens, W. Desmet, and H. Van Der Auweraer, "Application of the transmissibility concept in transfer path analysis," Mechanical Systems and Signal Processing, vol. 24, no. 7, pp. 1963-1976, 2010.

[22] SIEMENS, "Technical info issued: what is transfer path analysis," 2014, http://www.plm.automation.siemens.com/en_us/products/lms/testing/transfer-path-analysis.shtml\#lightview-close.

[23] D. S. Hwang, D. J. Hur, and H. S. Hwang, "Understanding algorithm of time domain transfer path analysis," in Proceedings of the KSME Autumn Conference, pp. 3173-3177, 2011.

[24] SIEMENS, "Technical info issued: how to perform transfer path analysis," 2014, http://www.plm.automation.siemens.com/ en_us/products/lms/testing/transfer-path-analysis.shtml\#lightview-close.

[25] P. E. F. Padilha and J. R. De Frana Arruda, "Comparison of estimation techniques for vibro-acoustic transfer path analysis," Shock and Vibration, vol. 13, no. 4-5, pp. 459-467, 2006.

[26] M. Toome, Operational transfer path analysis: a study of source contributions prediction at low frequency [M.S. thesis], Department of Applied Acoustics, Chalmers University of Technology, 2012.

[27] SIEMENS, "Technical info issued: advanced transfer path analysis techniques," 2014, http://www.plm.automation.siemens.com/ en_us/products/lms/testing/transfer-path-analysis.shtml\#lightview-close.

[28] M. Lee and M. Richardson, "Determining the accuracy of modal parameter estimation method," in Proceedings of the 10th International Modal Analysis Conference (IMAC '92), pp. 1-8, 1992.

[29] D. J. Ewins, Modal Testing: Theory, Practice and Application, Research Studies Press Ltd, 2nd edition, 2000.

[30] J. W. Park and H. E. Kim, "Impact energy measurement of hydraulic breaker," Key Engineering Materials, vol. 3, pp. 1669$1672,2006$. 


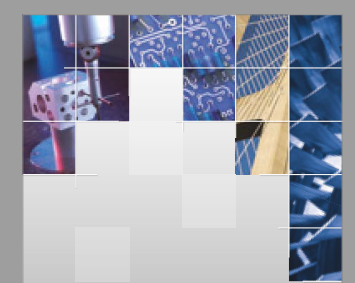

\section{Enfincering}
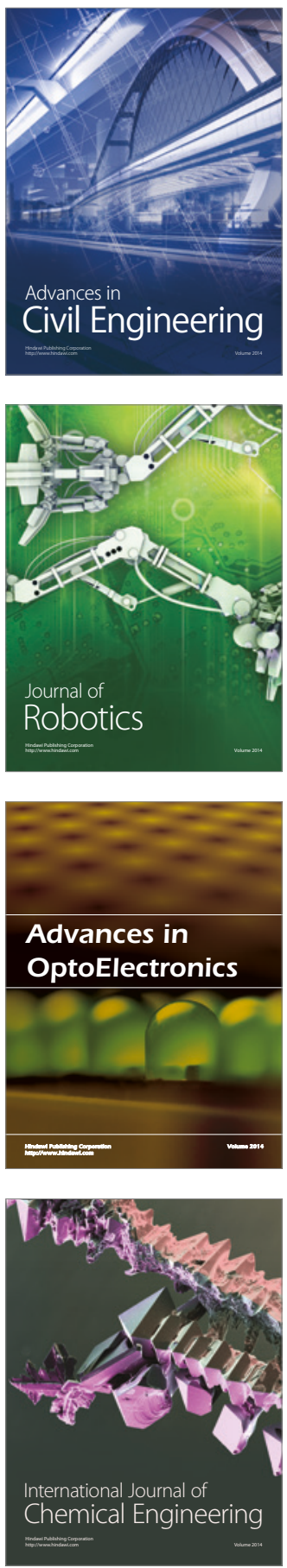

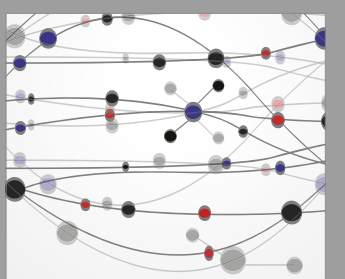

The Scientific World Journal

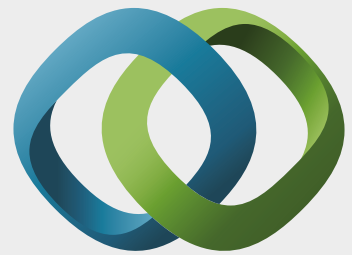

\section{Hindawi}

Submit your manuscripts at

https://www.hindawi.com
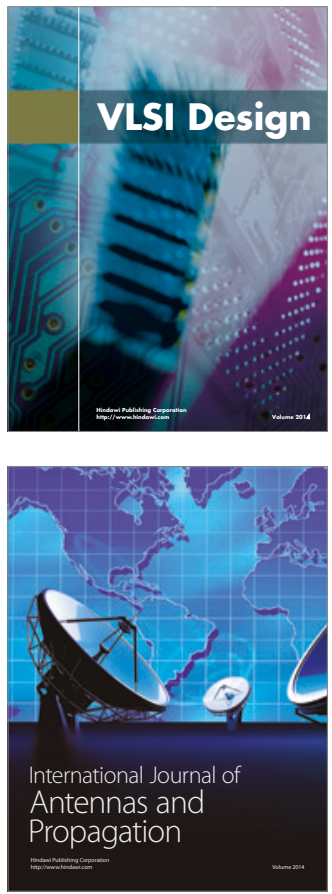

\section{Rotating}

Machinery
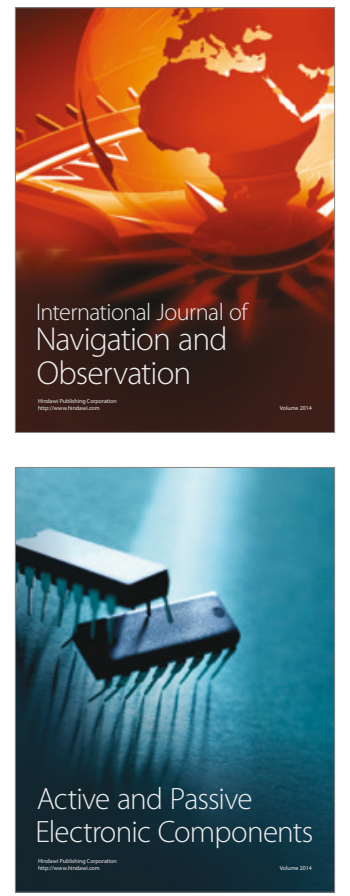
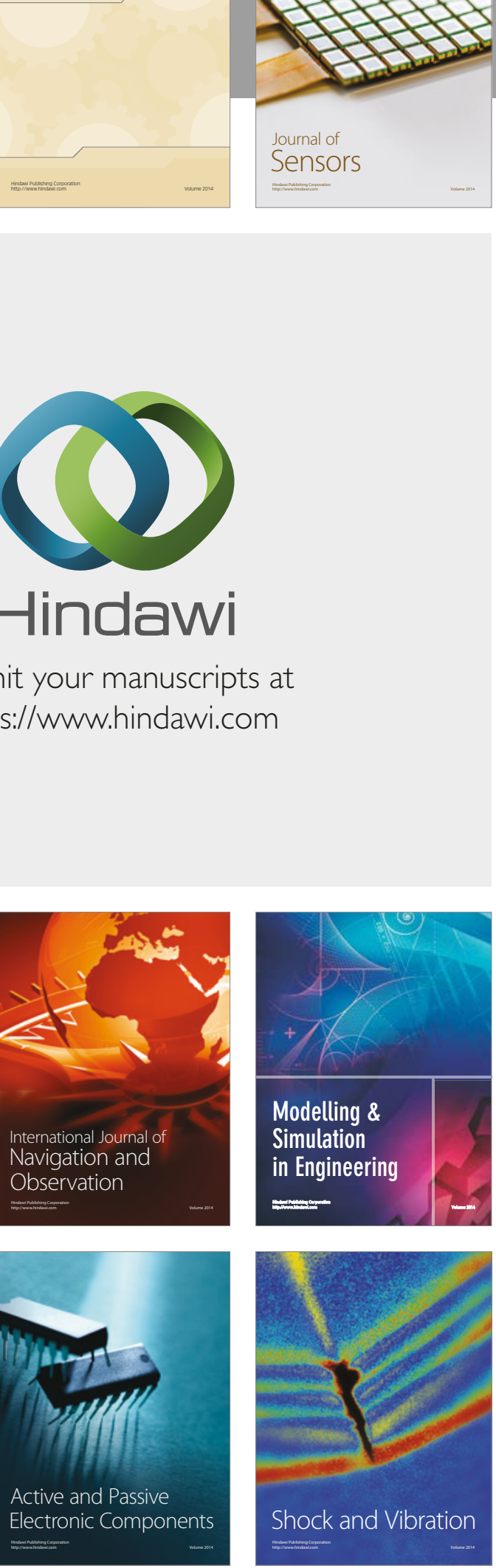
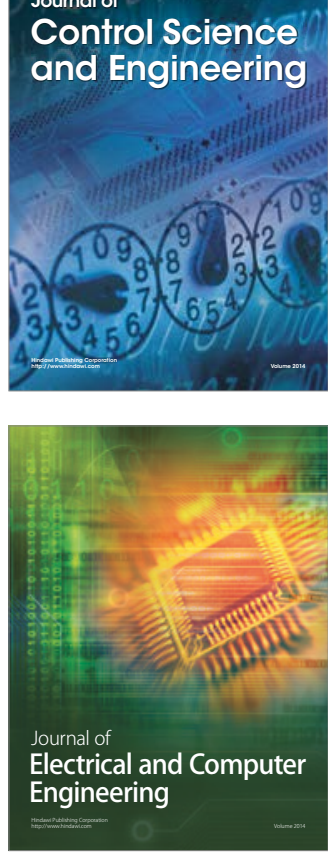

Distributed

Journal of

Control Science

and Engineering
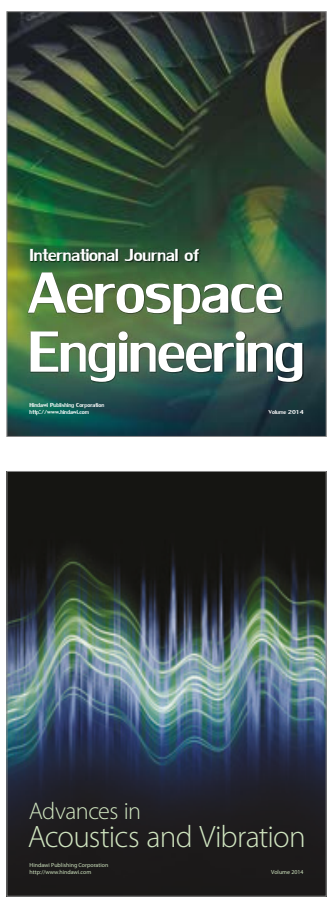

Sensor Networks 